\title{
Attitude of Iranian Medical Oncologists Toward Economic Aspects, and Policy-making in Relation to New Cancer Drugs
}

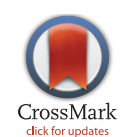

\author{
Rajabali Daroudi ${ }^{1,2}$, Mehrzad Mirzania $^{3}, K_{\text {Kazem Zendehdel }}{ }^{1,4^{*}}$
}

\begin{abstract}
Background: Although medical oncologists can have an important role in controlling the cost of cancer treatment, there is little information about their attitudes toward the cost of cancer treatment and the impact of cost on their treatment recommendations, especially in low- and middle-income countries (LMICs). In this study, we assessed the attitude of Iranian medical oncologists toward some economic aspects of new cancer drugs.

Methods: We translated a questionnaire that was used in similar studies in the United States and Canada into Persian and modified it according to the local setting in Iran. The face and content validity of the questionnaire were assessed by oncologists before being used in the survey. We distributed the questionnaire and collected the data from 80 oncologists who participated in the 13th Annual Congress of the Iranian Society of Medical Oncology and Hematology (ISMOH). Results: Fifty-two oncologists participated in our study (a response rate of 65\%). The majority of oncologists stated that drug costs and patient out-of-pocket (OOP) costs influence their treatment recommendations ( $92 \%$ and $94 \%$, respectively). Most oncologists (70\%) felt that they are ready enough to use cost-effectiveness information in their treatment decisions, and $74 \%$ believed that patients should only have access to cancer treatments that are cost-effective. Most oncologists agree that the government should have control over drug prices, and more use of cost-effectiveness data is required for decision-making about cancer drug coverage. Ninety-one percent of oncologists said that they always or frequently discuss cancer treatment costs with their patients. Oncologists believed that academic groups (research centers and scientific societies) (81\%) and the Ministry of Health $(\mathrm{MoH})(43 \%)$ are the most eligible groups for determining whether a drug provides good value.

Conclusion: Iranian medical oncologists are ready to participate in the health technology assessment and prioritysetting process. This situation creates a unique opportunity for the government to rely on scientific societies and find an appropriate solution for the improvement of patients' access to high-quality care.

Keywords: Medical Oncologists, Attitude, New Cancer Drugs, Cost, Policy-making, Iran.

Copyright: (c) 2016 by Kerman University of Medical Sciences

Citation: Daroudi R, Mirzania M, Zendehdel K. Attitude of Iranian medical oncologists toward economic aspects, and policy-making in relation to new cancer drugs. Int J Health Policy Manag. 2016;5(2):99-105. doi:10.15171/ijhpm.2015.186
\end{abstract}

Article History:

Received: 25 June 2015

Accepted: 11 October 2015

ePublished: 20 October 2015

*Correspondence to:

Kazem Zendehdel

Email: kzendeh@sina.tums.ac.ir

\section{Key Messages}

Implications for policy makers

- The high prices of new cancer drugs affect oncologists' treatment recommendations and their patients' access to effective treatments.

- Iranian medical oncologists agree that government should have control over drug prices.

- It seems that Iranian medical oncologists are ready to participate in the health technology assessment and priority-setting process.

Implications for public

Some of the new cancer drugs impose high financial costs on cancer patients, their families and society. Patient-physician communication about the clinical benefits and costs of chemotherapy drugs seems to be necessary during the decision-making process for treatment planning in cancer patients. Patients and their caregivers should take this opportunity and involve themselves in the discussion with their doctors. Clinicians should apply appropriate tools and methods to communicate with their patients and help them make appropriate decisions.

\section{Background}

Recently, the high price of new cancer drugs has created much debate in the medical literature and mass media. ${ }^{1-3}$ Despite a moderate impact of some new cancer drugs on patient survival and quality of life, their prices are very high, so most likely some of them are not cost-effective, especially in low- and middle-income countries (LMICs) whose cost-effectiveness threshold is low. ${ }^{4}$ According to the World Bank classification, LMICs are those who had a gross national income per capita of less than $\$ 12746$ in 2013. ${ }^{5}$ The World Health Organization (WHO) has recommended a cost-effectiveness threshold of less than 3 times the GDP per capita. ${ }^{6}$ However, Kantarjian et $\mathrm{al}^{7}$ showed in their article that most new cancer drugs cost more than $\$ 70000$ per patient annually in the United States. They stated that the correlation between the price of a new cancer drug and its effectiveness is low. Of 12 anticancer drugs approved by the U.S. Food and Drug Administration (FDA) in 2012, only 3 led to improvement in survival, of which 2 improved survival by less than 2 months. Although the price of drugs in the United States are somewhat higher than in other countries, ${ }^{2}$ it seems that, consistent with the WHO recommendation, most new cancer drugs may not be 
cost-effective in LMICs.

Although new cancer drugs improve patients' outcome, they impose high financial costs on patients, their families and health systems. ${ }^{4,8} 9$ The price of new cancer drugs is too high, so even the national health systems in high-income countries cannot publicly fund them. ${ }^{10}$ Thus patients have to pay drug costs out-of-pocket (OOP).

The public sector has the main role in the provision of healthcare in Iran. The private sector mostly provides secondary and tertiary care in urban areas. There are 3 major types of healthcare financing in Iran: general revenue financing, social healthcare insurance, and household OOP payments. The private healthcare insurance market is small in the country. However, before implementation of the Health Evolution Plan, around $10 \%$ of the population had no healthcare insurance coverage and more than $50 \%$ of healthcare costs were paid by patients. ${ }^{11}$ For cancer patients, the majority of OOP payments were for drugs costs. ${ }^{12}$ The Health Evolution Plan, which started in May 2014, has 3 main objectives: to provide financial protection against health expenditures, to enhance equity in access to healthcare services, and to improve the quality of healthcare services. ${ }^{13}$ In the first phase of the plan, the government insured more than 7 million people who were under no insurance previously, and covered up to $90 \%$ of hospitalization costs for insured patients at public hospitals. Preliminary evaluations have shown that the plan reduced OOP payments by $10 \% .{ }^{13}$ However, as most of the new and expensive cancer drugs are out of insurance coverage in Iran, patients must pay the drug costs OOP. OOP payments, therefore, drag patients into poverty or limit their access to effective treatments. ${ }^{4,14-16}$

The process of decision-making in relation to drug reimbursement in Iran is quite similar to other countries. In the process, several criteria, such as clinical effectiveness, safety, cost-effectiveness and budget impact, are used. However, the drug reimbursement system in Iran has several drawbacks, including high OOP payments, due to a lengthy decision-making process, a lack of transparency and conflicting stakeholder interests. ${ }^{17}$ Because of these shortcomings, the drug reimbursement system in Iran cannot assess and appraise new expensive cancer drugs quickly and accurately. For example, in 2010, several years after Trastuzumab had entered the market in Iran, health policymakers found that this drug imposed a significant financial burden on the Iranian patients and government, so the Ministry of Health $(\mathrm{MoH})$ decided to implement a national program for the regulation of Trastuzumab prescriptions in Iran. ${ }^{10}$ Another example was Nilotinib (Tasigna); it took more than one year to develop guidance for this drug by specialists and the guideline development office of the $\mathrm{MoH}$. In the guidance, Nilotinib was recommended as a secondor third-line treatment for chronic myeloid leukemia. But before implementation of the guidance, the Food and Drug Organization, which determines the drugs that are eligible for coverage by governmental subsidies, added Nilotinib to the subsidized drug list. As a result, the drug's sales increased about six times during the following year in Iran (from $\$ 1$ to $\$ 6$ million). ${ }^{18}$

On the other hand, the prevalence of cancer is increasing in the world, especially in LMICs, including Iran. ${ }^{19}$ Thus, new and expensive cancer treatments will impose a significant economic burden on LMICs in the future. Since most of these countries are facing a severe shortage of resources, they must look for ways to control cancer treatment costs. For example, in the last decade the cost of cancer drugs nearly doubled in Iran and reached about US\$350 million in 2014. More than $70 \%$ of the cost of cancer drugs is related to drugs imported from other countries. ${ }^{18}$

Medical oncologists can have an important role in controlling the cost of cancer treatments. ${ }^{20}$ They are the main decisionmakers in the treatment process and decide what medications a patient should use. ${ }^{21}$ Although oncologists want their patients to receive the treatment that provides the greatest benefit, however, they must also consider the costs of treatment, because high-cost treatment may impose a financial burden on patients and society and reduce their welfare. ${ }^{4}$

Previous studies in the United States, Canada, Australia, and Israel examined the attitude of medical oncologists toward the cost of new cancer drugs. ${ }^{3,22-26}$ The results of a survey of 1355 United States and 238 Canadian medical oncologists conducted by Berry et al showed that patient OOP costs influence the treatment recommendations of most oncologists in both countries (84\% the United States, $80 \%$ Canadian). Moreover, the majority of oncologists believed that governments should control the price of cancer drugs (57\% the United States, 68\% Canadian). ${ }^{22}$ In another survey of 167 US oncologists, $86 \%$ of respondents reported that they were aware of their patients' financial well-being. Furthermore, $80 \%$ of respondents strongly agreed or agreed that "it is important to be explicit with patients about the financial consequences of treatment options." ${ }^{24}$ Likewise the results of a survey of 184 Australian oncologists showed that the price of cancer drugs influences their treatment recommendations. ${ }^{25}$ Also, in a survey on 52 Israeli oncologists, $77 \%$ of them stated that inclusion of a cancer drug in the National List of Health Services influenced their treatment recommendations, and 92\% believed that it affected their patients' access to treatment. In addition, $73 \%$ believed that cost-effectiveness analysis should be used in coverage decisions for cancer drugs. ${ }^{26}$ Although medical oncologists can have an important role in controlling the cost of cancer treatment, there is little information about their attitudes toward the cost of cancer treatment and the impact of cost on their treatment recommendations, especially in LMICs. In this study, we assessed the attitudes of Iranian medical oncologists toward some economic aspects of cancer treatment, including the costs and cost-effectiveness of cancer drugs and related health policies.

\section{Methods}

This study was conducted with the coordination and support of the Iranian Society of Medical Oncology and Hematology (ISMOH). Almost all medical oncologists and hematologists in Iran are members of ISMOH and the society has about 200 members across the country. We used the convenience sampling method and conducted our survey during the 13th Annual Congress of ISMOH, where most Iranian oncologists were available and had time to complete the survey questions, assuming that they will be representative of the total Iranian oncologists. 
We used a questionnaire that was developed previously for the same purpose in the United States and Canada. ${ }^{3,22} \mathrm{We}$ translated the questionnaire into Persian and modified it for the local setting. The face and content validity of the questionnaire were assessed by a few oncologists before using the survey (the survey instrument can be found in Appendix 1). The questionnaire consisted of 14 statements and we asked oncologists to indicate their level of agreement with each statement on a 5-point Likert scale: strongly agree, somewhat agree, neither agree nor disagree, somewhat disagree, and strongly disagree.

We distributed the questionnaire among 80 oncologists who were participating in the 13th Annual Congress of ISMOH. The Congress team announced the survey in the main hall and asked the participants to complete the survey during the first day. The completed questionnaires were collected during the breaks and at the end of the day.

We used IBM SPSS 20 software (SPSS Inc., Chicago, IL) and performed descriptive data analysis.

\section{Results}

The response rate was $65 \%$ and 52 out of 80 participants completed the survey. Table 1 shows the characteristics of the respondents. The mean age of the study participants was 46 (range: 36-68) and 88\% were male. Most of the oncologists $(50 \%)$ practiced in both the public and private sectors. About $80 \%$ of the oncologists visited more than 50 patients per week. Table 2 shows oncologists' attitudes toward the cost of cancer drugs and cost-effectiveness. The majority of oncologists stated that drug costs and patient OOP costs influence their treatment recommendations ( $92 \%$ and $94 \%$, respectively). Moreover, most of the respondents believed that drug costs and patient OOP costs influence the ability of their patients to access treatments (96\% and $98 \%$, respectively). Seventy percent of oncologists strongly or somewhat agreed with the statement "I feel well-prepared to interpret and use cost-effectiveness information in my treatment decisions,"

Table 1. Demographic characteristics of the study sample

\begin{tabular}{lc}
\hline Mean Age (years) & 46 (Range: 36-68) (\%) \\
\hline Gender & 88 \\
Male & 12 \\
Female & \\
Practice setting & 46 \\
Public sector & 4 \\
Private sector & 50 \\
Public and private sector & \\
Time passed from subspecialty oncology & \\
training graduation (years) & 41 \\
$\leq 5$ & 23 \\
$6-10$ & 17 \\
$11-15$ & 13 \\
$16-20$ & 6 \\
$\geq 21$ & \\
Average number of patient per week & 17 \\
$\leq 50$ & 42 \\
$51-100$ & 14 \\
$101-150$ & 27 \\
$\geq 151$ &
\end{tabular}

and $74 \%$ of oncologists strongly or somewhat agreed that "Every Iranian patient should have access to effective cancer treatments only if the treatments provide 'good value for money' or are cost-effective." Ninety-one percent of oncologists said that they always or frequently discuss cancer treatment costs with their patients.

Seventy-four percent of respondents believed that "over the next five years, costs of new cancer drugs will impose a need for governments to further restrict publicly funded access to some new and effective therapies" (Table 3). Eighty-four percent of respondents strongly or somewhat agreed with the statement "Government price controls for cancer drugs are needed," and about $85 \%$ agreed that more use of costeffectiveness data is required for decision-making about cancer drug coverage. Furthermore, $87 \%$ believed that more research on the comparative effectiveness of cancer drugs is needed. Just $7 \%$ agreed that more cost sharing for payment of cancer drugs is needed by patients.

In response to the question "Who do you believe should determine whether a drug provides good value?" all oncologists stated that academic groups (research centers and scientific societies) (81\%) are the most eligible group for this position, followed by the $\mathrm{MoH}$ (43\%), insurance companies (11\%), and patients (11\%) (more than one option could be selected).

\section{Discussion}

Our study results show that the high prices of new cancer drugs affect oncologists' treatment recommendations and their patients' access to effective treatments. More than $90 \%$ of oncologists stated that drug costs influence their treatment recommendations and the ability of their patients to access treatments. In a study conducted in the United States, ${ }^{3} 56 \%$ of oncologists stated that the price of new cancer drugs affected their treatment recommendations and $84 \%$ of them stated that 'Patient 'OOP' drug costs currently influence my decisions regarding which cancer treatments to recommend for my patients." Also, in another study conducted in Canada, $80 \%$ of oncologists agreed with this statement. ${ }^{22}$

We found that Iranian oncologists discuss the costs of new cancer treatments with their patients (91\%) more than those in the United States (43\%), ${ }^{3}$ Canada (48\%), ${ }^{22}$ and Israel (17\%). ${ }^{26}$ This finding might be due to the fact that patients' OOP payments in Iran were more than those in these countries. As mentioned before, OOP payments amount to over $50 \%$ of the total medical cost in Iran while the share of OOP payments of the total cancer medical cost in the United States was 8\% during the 2001-2005 period. ${ }^{27}$ Using the WHO method and the threshold of $40 \%$ capacity to pay, and despite full health insurance coverage, about $68 \%$ of the households faced catastrophic health expenditures in a survey of 245 households with cancer patients in the Shiraz province of Iran in 2011. The risk of catastrophic health expenditures was significantly higher among patients who underwent chemotherapy. ${ }^{16}$ Berry et $\mathrm{al}^{20}{ }^{20}$ in their qualitative study in Canada, found that oncologists talk more with patients about access to drugs being limited due to funding decisions. The American Society of Clinical Oncology (ASCO) considers physician-patient communication about the cost of care to be an important component of high-quality care. ASCO 
Table 2. Attitude of the Iranian Oncologists $(\mathrm{N}=52)$ Towards Cancer Drugs' Costs and Cost-Effectiveness, 2014

\begin{tabular}{|c|c|c|c|c|c|}
\hline \multirow[b]{2}{*}{ Question } & \multicolumn{5}{|c|}{ Percent Stating } \\
\hline & $\begin{array}{l}\text { Strongly } \\
\text { Agree }\end{array}$ & $\begin{array}{l}\text { Somewhat } \\
\text { Agree }\end{array}$ & $\begin{array}{l}\text { Neither Agree } \\
\text { or Disagree }\end{array}$ & $\begin{array}{l}\text { Somewhat } \\
\text { Disagree }\end{array}$ & $\begin{array}{l}\text { Strongly } \\
\text { Disagree }\end{array}$ \\
\hline $\begin{array}{l}\text { The costs of new cancer drugs currently influence my decisions regarding which } \\
\text { cancer treatments to recommend for my patients }\end{array}$ & 62 & 30 & 0 & 8 & 0 \\
\hline $\begin{array}{l}\text { The costs of new cancer drugs currently influence my patients' ability to access } \\
\text { treatments. }\end{array}$ & 63 & 33 & 0 & 4 & 0 \\
\hline $\begin{array}{l}\text { Patient "out-of-pocket" drug costs currently influence my decisions regarding } \\
\text { which cancer treatments to recommend for my patients. }\end{array}$ & 56 & 38 & 2 & 4 & 0 \\
\hline $\begin{array}{l}\text { Patient "out-of-pocket" drug costs currently influence my patients' ability to } \\
\text { access treatments. }\end{array}$ & 63 & 35 & 2 & 0 & 0 \\
\hline $\begin{array}{l}\text { I feel well-prepared to interpret and use cost-effectiveness information in my } \\
\text { treatment decisions. }\end{array}$ & 30 & 40 & 17 & 13 & 0 \\
\hline $\begin{array}{l}\text { Every Iranian patient should have access to effective cancer treatments regardless } \\
\text { of their cost. }\end{array}$ & 21 & 39 & 20 & 16 & 4 \\
\hline \multirow[t]{2}{*}{$\begin{array}{l}\text { Every Iranian patient should have access to effective cancer treatments only if the } \\
\text { treatments provide "good value for money" or are cost-effective. }\end{array}$} & 46 & 28 & 13 & 11 & 2 \\
\hline & \multicolumn{5}{|c|}{ Percent Frequency $(\mathrm{N}=52)$} \\
\hline \multicolumn{6}{|l|}{ How often do you discuss the costs of new cancer treatments with your patients? } \\
\hline Always & \multicolumn{5}{|c|}{29} \\
\hline Frequently & \multicolumn{5}{|c|}{62} \\
\hline Occasionally & \multicolumn{5}{|c|}{6} \\
\hline Rarely & \multicolumn{5}{|c|}{1} \\
\hline Never & \multicolumn{5}{|c|}{2} \\
\hline
\end{tabular}

Since we used the Berry et $a^{22}$ study questionnaire in our study, therefore, the statements in the table are the same as those presented in their study.

Table 3. Attitude of the Iranian Oncologists $(\mathrm{N}=52)$ Toward Cancer Drugs-Related Health Policies, 2014

\begin{tabular}{|c|c|c|c|c|c|}
\hline \multirow[b]{2}{*}{ Question } & \multicolumn{5}{|c|}{ Percent Stating } \\
\hline & $\begin{array}{l}\text { Strongly } \\
\text { Agree }\end{array}$ & $\begin{array}{l}\text { Somewhat } \\
\text { Agree }\end{array}$ & $\begin{array}{l}\text { Neither Agree } \\
\text { or Disagree }\end{array}$ & $\begin{array}{l}\text { Somewhat } \\
\text { Disagree }\end{array}$ & $\begin{array}{l}\text { Strongly } \\
\text { Disagree }\end{array}$ \\
\hline $\begin{array}{l}\text { Over the next } 5 \text { years, costs of new cancer drugs will impose a need for governments } \\
\text { to further restrict publicly funded access to some new and effective therapies. }\end{array}$ & 34 & 40 & 20 & 6 & 0 \\
\hline Government price controls for cancer drugs are needed. & 59 & 25 & 8 & 6 & 2 \\
\hline More cost-sharing by patients for payment of cancer drugs is needed. & 3 & 4 & 10 & 60 & 23 \\
\hline More use of cost-effectiveness data in funding decisions for cancer drugs is needed. & 56 & 29 & 6 & 6 & 2 \\
\hline \multirow[t]{2}{*}{ More research on the comparative effectiveness of cancer drugs is needed. } & 48 & 39 & 7 & 6 & 0 \\
\hline & \multicolumn{5}{|c|}{ Percent Frequency $(\mathrm{N}=52)$} \\
\hline \multicolumn{6}{|l|}{ Who do you believe should determine whether a drug provides good value? } \\
\hline Ministry of health & \multicolumn{5}{|c|}{43} \\
\hline Insurance companies & \multicolumn{5}{|c|}{11} \\
\hline Patients & \multicolumn{5}{|c|}{11} \\
\hline Academic groups (research centers and scientific societies) & \multicolumn{5}{|c|}{81} \\
\hline Other & \multicolumn{5}{|c|}{6} \\
\hline
\end{tabular}

Since we used the Berry et $\mathrm{l}^{22}$ study questionnaire in our study, therefore, the statements in the table are the same as those presented in their study.

a Not mutually exclusive.

recommends that oncologists, in addition to direct medical costs, should consider direct nonmedical costs, such as travel costs and patient time cost, in relation to treatment options. Just recently, and in order to help oncologists involve patients in decision-making about clinical benefits and costs, ASCO designed and published a conceptual framework for assessing the value of new cancer treatment options based on clinical benefits, side effects and costs. The framework emphasizes the physician's role as the patient's trusted advocate, as well as their responsibility to be a good steward of healthcare resources who should facilitate patients' access to both clinical and cost information about their treatment options. ${ }^{28}$
Previous studies have shown that despite cancer patients' interest, usually only a few of them have the opportunity to discuss the cost of care with their physicians. ${ }^{8,29-32}$ In a survey on 45 Australian breast cancer patients conducted by Kaser et al, ${ }^{29}$ although $96 \%$ of patients wanted to discuss an expensive drug as an option with their oncologist, only $28 \%$ had discussed high-cost drugs treatment with their oncologist. In another survey on 134 breast cancer patients conducted by Irwin et $\mathrm{al},{ }^{32}$ most of the patients (94\%) believed that physicians should discuss costs of care with patients, while only $14 \%$ of them discussed costs with their doctor. Likewise, the results of Bestvina et $\mathrm{al}^{33}$ study on 300 cancer patients showed that only 
$19 \%$ of patients had talked about costs with their oncologist, while $27 \%$ had reported nonadherence to medication and $22 \%$ did not fill a prescription because of the costs. Although, as is shown in some studies, ${ }^{24}$ most oncologists think that they are aware of their patients' financial status, these data may refute such a perception of oncologists. Despite this, little is known about barriers to patient-oncologist communication in relation to the cost of care. Thus, it is important to identify the barriers and develop practical guidelines regarding cost communication.

In Berry et al study, ${ }^{22}$ less than half of the oncologists in the United States and Canada feel well-prepared to use costeffectiveness information, whereas in our study a greater percentage of oncologists $(70 \%)$ feel ready to use costeffectiveness information. In recent years, the increased cost of cancer treatment and high OOP payments in Iran have led oncologists to consider cost-effectiveness data in their treatment recommendations. In addition, the majority of oncologists in our study practice in the public sector and usually there is more emphasis on the cost-effectiveness of interventions in the this sector.

The percentage of Iranian oncologists who believe that every patient should only have access to cost-effective drugs (74\%) was similar to that among Canadian oncologists (75\%) but was higher than among US oncologists (58\%). ${ }^{22}$

In our study, the majority of oncologists believed that the government should have control over drug prices. In addition, most oncologists believed that more cost-effectiveness studies should be done and the results of these studies should be used in the decision-making process for drug funding. These findings indicate that Iranian oncologists are ready to help and support the government and health policy-makers in conducting economic evaluation studies and using the results of these studies in drug funding policy-making. Other countries' experience has shown that health technology assessments and the use of their results in the allocation of resources can help make better use of available resources. ${ }^{9}$ Although the $\mathrm{MoH}$ and insurance companies currently determine whether a drug is cost-effective in Iran, ${ }^{17}$ the oncologists emphasized the importance of the role of academic groups, including university research centers and scientific societies, in making decisions about the cost-effectiveness of drugs. In Berry et al study, ${ }^{22}$ both the United States and Canadian oncologists believed that nonprofit agencies and physicians should determine whether a drug provides good value.

Oncologists have an important role in the decision-making process for drug reimbursement. They usually make decisions on behalf of the patients and decide what treatment the patients should receive. In addition, clinical societies are too strong and may interfere with the decisions made by policy-makers. ${ }^{34}$ We found that although there are several shortcomings in the drug reimbursement system in Iran, Iranian oncologists are ready to help policy-makers overcome these limitations. This can be done through oncologists' involvement in clinical research and the provision of required data about the costs and effectiveness of cancer drugs. Oncologists can also have crucial roles in the development of clinical practice guidelines.

Clinical practice guidelines are one of the tools that can help to improve the quality of treatment and reduce its cost. Incorporating cost-effectiveness information into the guideline development process can reduce the cost of care..$^{35} \mathrm{~A}$ small number of clinical guidelines have been developed and localized in Iran so far, and most of them face serious problems in their implementation. According to Baradaran-Seyed et $\mathrm{al}^{36}$ study, the "lack of an evidence-based stewardship for the healthcare system" and "the level of knowledge, attitude and the abilities of the practitioner" were the most important barriers in the development and implementation of clinical guidelines in Iran. Oncologists and scientific societies, therefore, can play a major role in the removal of these barriers and the fostering of an evidence-based clinical practice in cancer care.

To the best of our knowledge, this study is the first attempt to examine oncologists' attitude toward the economic aspect of treatments in Iran. However, we faced some limitations. Only the oncologists who participated in the 13th Annual Congress of ISMOH were included in the study. However, although the sample size was small and may not be representative of all Iranian oncologists, most of the prominent and experienced oncologists participated in this congress and the results can be generalized to all Iranian oncologists. However, with the insights gathered from this study, it would be useful to conduct new studies in the future and apply other sampling methods to involve larger members of ISMOH. Furthermore, researchers have only analyzed the opinion of the oncologists on the impact of drug expenses on cancer care. It would also be informative to conduct parallel studies and compare the results from other stakeholders, in particular cancer patients and their caregivers.

In conclusion, this study has shown that the high cost of new cancer drugs influences oncologists' treatment recommendations and patients' access to these cancer drugs in Iran. Oncologists need to put more time and effort into communication with their patients. Therefore, they are ready to support scientific evaluation of the economic burden of drugs in the country and participate in health technology assessments and the priority-setting process in order to optimize patients' access to new expensive drugs. This situation creates a unique opportunity for the government to rely on scientific societies and find an appropriate solution for the improvement of patients' access to high-quality care and essential chemotherapy drugs.

\section{Acknowledgements}

This study was supported by Tehran University of Medical Sciences, Tehran, Iran (grant number 93-03-51-27025). We would also like to acknowledge the Iranian Society of Medical Oncology and Hematology (ISMOH) for support of this work.

\section{Ethical issues}

The study was approved by the Deputy of Research and Technology of the Tehran University of Medical Sciences, Tehran, Iran (code: 93-03-51-27025). The participants were assured that their information would remain confidential. The manuscript does not contain clinical studies or patient data. 
Authors' contributions

RD was involved in the study design, data collection, analysis, and drafting of the manuscript. MM contributed to the study design and data collection. $\mathrm{KZ}$ was involved in the study design and drafting of the manuscript. All the authors read and approved the final manuscript.

\section{Authors' affiliations}

${ }^{1}$ Cancer Research Center, Cancer Institute of Iran, Tehran University of Medical Sciences, Tehran, Iran. ${ }^{2}$ Department of Health Economics and Management, School of Public Health, Tehran University of Medical Sciences, Tehran, Iran. ${ }^{3}$ Hematology and Medical Oncology Department, Cancer Research Center, Cancer Institute, Imam Khomeini Hospital Complex, Tehran University of Medical Sciences, Tehran, Iran. ${ }^{4}$ Cancer Model Research Center, Cancer Institute of Iran, Tehran University of Medical Sciences, Tehran, Iran.

\section{References}

1. Rosamond T. The high cost of cancer drugs and what we can do about it. Paper presented at: Mayo Clinic Proceedings; 2013.

2. Experts in Chronic Myeloid Leukemia. The price of drugs for chronic myeloid leukemia $(\mathrm{CML})$ is a reflection of the unsustainable prices of cancer drugs: from the perspective of a large group of CML experts. Blood. 2013;121(22):4439-4442. doi:10.1182/blood-2013-03-490003

3. Neumann PJ, Palmer JA, Nadler E, Fang C, Ubel P. Cancer therapy costs influence treatment: a national survey of oncologists. Health Affairs. 2010;29(1):196-202. doi:10.1377/ hlthaff.2009.0077

4. Meropol NJ, Schrag D, Smith TJ, et al. American Society of Clinical Oncology guidance statement: the cost of cancer care. J Clin Oncol. 2009;27(23):3868-3874. doi:10.1200/ jco.2009.23.1183

5. The World Bank Data. Country and Lending Groups. http://data. worldbank.org/about/country-and-lending-groups. Accessed May 13, 2015.

6. Marseille E, Larson B, Kazi DS, Kahnd JG, Rosenb S. Thresholds for the cost-effectiveness of interventions: alternative approaches. Bull World Health Organ. 2015;93(2):65-132.

7. Kantarjian HM, Fojo T, Mathisen M, Zwelling LA. Cancer drugs in the United States: Justum Pretium-the just price. J Clin Oncol. 2013;31(28):3600-3604. doi:10.1200/jco.2013.49.1845

8. Bullock AJ, Hofstatter EW, Yushak ML, Buss MK. Understanding patients' attitudes toward communication about the cost of cancer care. J Oncol Pract. 2012;8(4):e50-e58. doi:10.1200/ jop.2011.000418

9. Shih YCT, Halpern MT. Economic evaluations of medical care interventions for cancer patients: how, why, and what does it mean? CA: A Cancer Journal for Clinicians. 2008;58(4):231-244. doi:10.3322/ca.2008.0008

10. Rouhollahi M, Mohamdnejad S, Harirchil, etal. Recommendations for management of the Trastuzumab (Herceptin) among Iranian breast cancer patients, a policy brief. Basic \& Clinical Cancer Research. 2014;6(2):27-34.

11. Hajizadeh M, Nghiem HS. Out-of-pocket expenditures for hospital care in Iran: who is at risk of incurring catastrophic payments? Int J Health Care Finance Econ. 2011;11(4):267-285. doi:10.1007/s10754-011-9099-1

12. Bazyar M, Pourreza A, Harirchi I, Akbari F, Mahmoudi M. Medical and non-medical direct costs of cancers in patients hospitalized in Imam Khomeini cancer institution - 2010. Hospital Journal. 2012;11 (1):39-50.

13. Ministry of Health and Medical Education (MoHME), Internatinal Affairs Departement. Health Evolution Plan in the Islamic Republic of Iran. http://ird.behdasht.gov.ir/index.aspx?fkeyid=\& siteid $=419$ \&pageid $=51060$ \&newsview $=113776$. Accessed July 27, 2015.

14. Alexander GC, Casalino LP, Tseng CW, McFadden D, Meltzer DO. Barriers to patient-physician communication about out- of-pocket costs. J Gen Intern Med. 2004;19(8):856-860. doi:10.1111/j.1525-1497.2004.30249.x

15. Pouragha B, Pourreza A, Jaafaripooyan E, et al. The effect of access and out of pocket payment on the utilization of physicians services. World Appl Sci J. 2013;22(1):104-112.

16. Delavari H, Keshtkaran A, Setoudehzadeh F. Catastrophic health expenditures and coping strategies in households with cancer patients in Shiraz Namazi hospital. Middle East Journal of Cancer. 2014;5(1):13-22.

17. Ansaripour A, Uyl-de Groot CA, Steenhoek A, Redekop WK. The drug reimbursement decision-making system in Iran. Value in Health Regional Issues. 2014;3:174-181.

18. Drug Deputy of Iran Food and Drug Organization. The Drug Sales Statistics During 2014 (AmarNameh). Tehran, Iran: Ministry of Health and Medical Education; 2015.

19. Ferlay J, Soerjomataram I, Dikshit R, et al. Cancer incidence and mortality worldwide: sources, methods and major patterns in GLOBOCAN 2012. Int J Cancer. 2015;136(5):E359-E386. doi:10.1002/ijc.29210

20. Berry SR, Hubay S, Soibelman H, Martin DK. The effect of priority setting decisions for new cancer drugs on medical oncologists' practice in Ontario: a qualitative study. BMC Health Serv Res. 2007;7(1):193. doi:10.1186/1472-6963-7-193

21. de Kort SJ, Kenny N, van Dijk P, Gevers S, Richel DJ, Willems DL. Cost issues in new disease-modifying treatments for advanced cancer: In-depth interviews with physicians. Eur J Cancer. 2007;43(13):1983-1989. doi:10.1016/j.ejca.2007.05.017

22. Berry SR, Bell CM, Ubel PA, et al. Continental divide? The attitudes of US and Canadian oncologists on the costs, costeffectiveness, and health policies associated with new cancer drugs. J Clin Oncol. 2010;28(27):4149-4153. doi:10.1200/ jco.2010.29.1625

23. Nadler E, Eckert B, Neumann PJ. Do oncologists believe new cancer drugs offer good value? Oncologist. 2006;11(2):90-95.

24. Schrag D, Hanger M. Medical oncologists' views on communicating with patients about chemotherapy costs: A pilot survey. J Clin Oncol. 2007;25(2):233-237. doi:10.1200/ jco.2006.09.2437

25. Thomson J, Schofield P, Mileshkin L, et al. Do oncologists discuss expensive anti-cancer drugs with their patients? Ann Oncol. 2006;17(4):702-708. doi:10.1093/annonc/mdj136

26. Greenberg D, Hammerman A, Vinker S, Shani A, Yermiahu Y, Neumann PJ. Oncologists' and family physicians' views on value for money of cancer and congestive heart failure care. Isr $J$ Health Policy Res. 2013;2:44. doi:10.1186/2045-4015-2-44

27. Tangka FK, Trogdon JG, Richardson LC, Howard D, Sabatino SA, Finkelstein EA. Cancer treatment cost in the United States. Cancer. 2010;116(14):3477-3484. doi:10.1002/cncr.25150

28. Schnipper LE, Davidson NE, Wollins DS, et al. American society of clinical oncology statement: a conceptual framework to assess the value of cancer treatment options. $J$ Clin Oncol. 2015;33(23):2563-2577. doi:10.1200/JCO.2015.61.6706

29. Kaser E, Shaw J, Marven M, Swinburne L, Boyle F. Communication about high-cost drugs in oncology - the patient view. Ann Oncol. 2010;21(9):1910-1914. doi:10.1093/annonc/ mdq068

30. Henrikson NB, Tuzzio L, Loggers ET, Miyoshi J, Buist DS. Patient and oncologist discussions about cancer care costs. Support Care Cancer. 2014;22(4):961-967. doi:10.1007/s00520013-2050-x

31. Hofstatter EW. Understanding patient perspectives on communication about the cost of cancer care: a review of the literature. J Oncol Pract. 2010;6(4):188-192. doi:10.1200/ jop.777002

32. Irwin B, Kimmick G, Altomare I, et al. Patient experience and attitudes toward addressing the cost of breast cancer care. 


\section{Oncologist. 2014;19(11):1135-1140.}

33. Bestvina CM, Zullig LL, Rushing C, et al. Patient-oncologist cost communication, financial distress, and medication adherence. $J$ Oncol Pract. 2014;10(3):162-167. doi:10.1200/jop.2014.001406

34. Rosenberg-Yunger ZR, Thorsteinsdóttir H, Daar AS, Martin DK. Stakeholder involvement in expensive drug recommendation decisions: an international perspective. Health Policy. 2012;105(2):226-235. doi:10.1016/j.healthpol.2011.12.002
35. Pfister DG. The just price of cancer drugs and the growing cost of cancer care: oncologists need to be part of the solution. J Clin Oncol. 2013;31(28):3487-3489. doi:10.1200/jco.2013.50.3466

36. Baradaran-Seyed Z, Nedjat S, Yazdizadeh B, Nedjat S, Majdzadeh R. Barriers of clinical practice guidelines development and implementation in developing countries: a case study in iran. Int J Prev Med. 2013;4(3):340.

Appendix 1

Survey of Iranian medical oncologists' attitude towards economic aspects, and policy-making in relation to new cancer drugs Section I: Demographic Information (Please indicate or fill-in your response)

1- Gender: $\square \mathrm{M} \square \mathrm{F}$

2- Age: ..........year

3- Main practice setting:

$\square$ Public sector

$\square$ Private sector

$\square$ Public and private sector

4- $\quad$ Time passed from your subspecialty oncology training graduation: ........................year

5- Average number of patients you visit: ................ patients per week

\section{Section II: Attitudes}

\begin{tabular}{|c|c|c|c|c|c|c|}
\hline \multicolumn{2}{|r|}{ Please Indicate How Much You Agree or Disagree With the Following Statements: } & \multirow[t]{2}{*}{$\begin{array}{l}\text { Strongly } \\
\text { Agree }\end{array}$} & \multirow[t]{2}{*}{$\begin{array}{l}\text { Somewhat } \\
\text { Agree }\end{array}$} & \multirow[t]{2}{*}{$\begin{array}{l}\text { Neither } \\
\text { Agree or } \\
\text { Disagree }\end{array}$} & \multirow[t]{2}{*}{$\begin{array}{l}\text { Somewhat } \\
\text { Disagree }\end{array}$} & \multirow[t]{2}{*}{$\begin{array}{l}\text { Strongly } \\
\text { Disagree }\end{array}$} \\
\hline 6 & $\begin{array}{l}\text { The costs of new cancer drugs currently influence my decisions regarding which } \\
\text { cancer treatments to recommend for my patients }\end{array}$ & & & & & \\
\hline 7 & $\begin{array}{l}\text { The costs of new cancer drugs currently influence my patients' ability to access } \\
\text { treatments. }\end{array}$ & & & & & \\
\hline 8 & $\begin{array}{l}\text { Patient "out-of-pocket" drug costs currently influence my decisions regarding } \\
\text { which cancer treatments to recommend for my patients. }\end{array}$ & & & & & \\
\hline 9 & $\begin{array}{l}\text { Patient "out-of-pocket" drug costs currently influence my patients' ability to } \\
\text { access treatments. }\end{array}$ & & & & & \\
\hline 10 & $\begin{array}{l}\text { I feel well-prepared to interpret and use cost-effectiveness information in my } \\
\text { treatment decisions. }\end{array}$ & & & & & \\
\hline 11 & $\begin{array}{l}\text { Every Iranian patient should have access to effective cancer treatments } \\
\text { regardless of their cost. }\end{array}$ & & & & & \\
\hline 12 & $\begin{array}{l}\text { Every Iranian patient should have access to effective cancer treatments only if } \\
\text { the treatments provide "good value for money" or are cost-effective. }\end{array}$ & & & & & \\
\hline 13 & $\begin{array}{l}\text { Over the next } 5 \text { years, costs of new cancer drugs will impose a need for } \\
\text { governments to further restrict publicly funded access to some new and effective } \\
\text { therapies. }\end{array}$ & & & & & \\
\hline 14 & Government price controls for cancer drugs are needed. & & & & & \\
\hline 15 & More cost-sharing by patients for payment of cancer drugs is needed. & & & & & \\
\hline 16 & $\begin{array}{l}\text { More use of cost-effectiveness data in funding decisions for cancer drugs is } \\
\text { needed. }\end{array}$ & & & & & \\
\hline 17 & More research on the comparative effectiveness of cancer drugs is needed. & & & & & \\
\hline
\end{tabular}

18- How often do you discuss the costs of cancer treatments with your patients? (Please check answer)

$\square$ Always $\quad \square$ Frequently $\quad \square$ Occasionally $\quad \square$ Rarely $\quad \square$ Never

19- Who do you believe should determine whether a drug provides good value? (Please check all that apply)

$\square$ Ministry of health

$\square$ Patients

$\square$ Insurance companies

$\square$ Academic groups (research centers and scientific societies)

$\square$ Other (please specify): ...... 